\title{
Unit Commitment Problem in Electrical Power System: A Literature Review
}

\author{
IdrissAbdou, Mohamed Tkiouat \\ Laboratory of Study and Research in Applied Mathematics (LERMA), Engineers' Mohammadia School, EMI, \\ UMV Rabat, Morocco
}

\begin{tabular}{l} 
Article Info \\
\hline Article history: \\
Received Jan 11, 2018 \\
Revised Mar 13, 2018 \\
Accepted Mar 27, 2018 \\
\hline
\end{tabular}

Keyword:

Generation scheduling Mixed integer linear programming Optimization methods Stochastic programming Uncertainty Unit commitment

\section{Corresponding Author:}

Idriss Abdou,

Laboratory of Study and Research in Applied Mathematics (LERMA),

Engineers Mohammadia School, EMI, UMV Rabat, Morocco.

Email: idriss.abdou92@gmail.com

\begin{abstract}
Unit commitment (UC) is a popular problem in electric power system that aims at minimizing the total cost of power generation in a specific period, by defining an adequate scheduling of the generating units. The UC solution must respect many operational constraints. In the past half century, there was several researches treated the UC problem. Many works have proposed new formulations to the UC problem, others have offered several methodologies and techniques to solve the problem. This paper gives a literature review of UC problem, its mathematical formulation, methods for solving it and Different approaches developed for addressing renewable energy effects and uncertainties.
\end{abstract}

Copyright $@ 2018$ Institute of Advanced Engineering and Science. All rights reserved.

\section{INTRODUCTION}

Unit commitment (UC) is among the most important and critical problems in the electrical power industry. UC refers to the task of finding an optimal schedule and a production level for power system's each generating unit over a given time period, subject to a given load forecast and spinning reserve constraints [1], [2]. The goal behind UC problem is to balance demand with production while optimizing resources and costs [3]. In fact, the electricity markets are facing several challenges in different stages: generation, transmission and distribution. The main problems in electrical power systems are UC, variation of consumer demand in electricity, environment problems related to use of fossil fuels, intermittence of renewable sources and failure of system components. In this paper, we focus on representing a literature review of UC problem.

The classifications of UC problem are different. With respect to security, UC is divided into three categories: traditional UC, security-constrained UC (SCUC) and price-based unit commitment (PBUC) [4]. From the market operation's perspective, UC can be classified by either scheduling in a vertically integrated environment or in a deregulated environment. Compared to the treatment of future events, UC is separated into deterministic and stochastic UC [5].

Recently, higher generation from renewable energy sources (RES) and more price responsive demand participation have made the UC problem a hard challenge, mainly due to the unpredictability and the high variability of RES. It became necessary to have an effective methodology that produces robust UC decisions and secures the system reliability face of the increasing real-time uncertainty [6]. Otherwise, the progress in renewable energy technology has been extraordinary in recent years. Various computer models have been developed to facilitate the implementation of renewable power projects especially for the choice and design of renewable energy sources. Among them, HOMER, RETScreen, and DER-CAM. For example, HOMER (Hybrid Optimization of Multiple Energy Resources) is a software of simulation and optimization 
intended for the study of multi-sources power generation facilities such as PV, wind energy, network, and storage. It is mainly utilized for the simulation of connected or non-connected off grids [7]. Following the described research trend, this paper aims to revisit UC problem formulations (deterministic and stochastic) and to provide a global review of the researches and studies treating UC problem included the latest models of UC proposed in the context of high penetration of renewable energy. Several methods and techniques to get an optimal generation scheduling in both regulated and deregulated power markets have been proposed. Within this framework, we provide a survey of optimization techniques used to solve the UC problem.

The paper is organized as follows. Section 2 presents the evolution of UC problem over the past years. Section 3 provides the classic mixed integer linear formulation of UC problem. In Section 4 we will focus on the stochastic programming's application in UC problem to deal with uncertainty in power system. Section 5 provides a review of methods that have been proposed in the past few decades for UC problem optimization. We end the paper with some concluding remarks in Section 6.

\section{OVERVIEW OF THE UC PROBLEM}

Unit commitment (UC) is a problem widely treated by the researchers since 1940s [8]. Given the enormous volume of papers in this field, several review articles have been presented. Divers optimization methods for solving UC problem are outlined. It also points out UC's different considerations in both regulated and deregulated environments. Lately, with an increased incorporation of RES and the implementation of energy storage devices, power systems' operation strategies have known significant modifications [5]. Some articles such as [3] have given a review of recent approaches to UC problem in the presence of intermittent RES. Figure 1 gives an overview of the evolution of the problem since its appearance until now. In the same context, Table 1 (appendix) provides a detailed review of the history of UC problem through time by representing the remarkable publications.

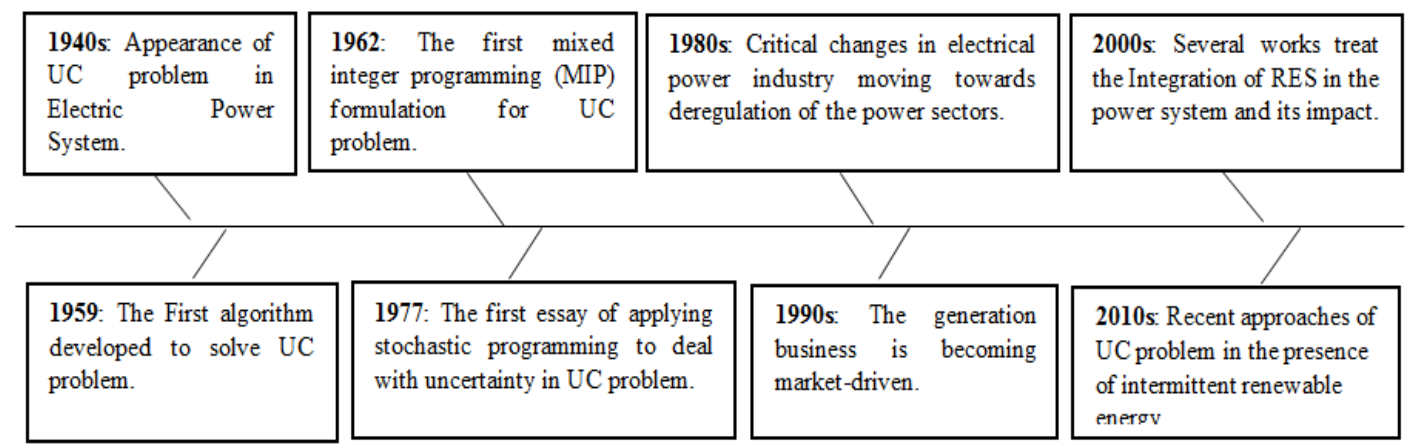

Figure 1. Summary of UC problem's evolution through time

In general, UC is NP-hard optimization problem [9], where the System operator (SO) aims at minimizing the total production cost over the scheduling horizon. In general, the total production cost comprises fuel costs, which are related to operation of thermal units, start-up costs, and shutdown costs. As a result, the UC problem has been traditionally solved in power systems to determine the best possible commitment status, the start-up/shutdown sequences, and the power outputs for all available units, subject to various constraints [10]. Usually, there are three types of generating units in electrical power systems: thermal units (include nuclear units), hydro units, and RES units.

In this sense, the UC optimization problem has the following form [6]:

Total production costs $=$ Fuel cost + Start-up cost + Shutdown cost + Maintenance cost

To be minimized.

Other costs such as no-load served cost and investment cost can be adding to UC problem formulation. This minimization depends on many constraints related to operation of generating units and system power equilibrium (presented inSection 3) 
Table 1. UC Problem Development, from 1940 to 2017

\begin{tabular}{|c|c|c|c|}
\hline Year & Type of problem & General idea & References \\
\hline 1940s & $\begin{array}{l}\text { Formulation of UC } \\
\text { problem }\end{array}$ & Appearance of UC problem in electrical energy systems. & [8] \\
\hline 1959 & $\begin{array}{l}\text { Solution to UC } \\
\text { problem }\end{array}$ & $\begin{array}{l}\text { An algorithm called PL (priority list) scheme was proposed, in which generating units } \\
\text { status were decided according to their average production costs. }\end{array}$ & [11] \\
\hline 1962 & $\begin{array}{l}\text { Formulation of UC } \\
\text { problem }\end{array}$ & $\begin{array}{l}\text { The first MIP formulation for UC problem was proposed by the authors, in which } \\
\text { three binary variables are used to represent the unit statuses (ON/OFF, start-up and } \\
\text { shutdown). The model is known as the } 3 \text {-bin formulation. }\end{array}$ & [12] \\
\hline 1966 & $\begin{array}{l}\text { Solution to UC } \\
\text { problem }\end{array}$ & $\begin{array}{l}\text { The UC problem has been solved by enumerating all possible combinations of the } \\
\text { generating units and then the combinations that produce the minimized cost are } \\
\text { chosen as the optimal solution. }\end{array}$ & {$[13]$} \\
\hline 1975 & $\begin{array}{l}\text { Solution to UC } \\
\text { problem }\end{array}$ & The authors utilized Priority listing method to handle UC problem. & {$[14]$} \\
\hline \multirow[t]{3}{*}{1977} & $\begin{array}{l}\text { Solution to UC } \\
\text { problem }\end{array}$ & An application of Lagrangian relaxation to scheduling in power systems. & {$[15]$} \\
\hline & $\begin{array}{l}\text { Stochastic } \\
\text { programming to } \\
\text { solve UC problem }\end{array}$ & $\begin{array}{l}\text { The first essay of applying Stochastic programming to solve UC problem with } \\
\text { uncertainties. }\end{array}$ & {$[16]$} \\
\hline & $\begin{array}{l}\text { Formulation of UC } \\
\text { problem }\end{array}$ & $\begin{array}{l}\text { The production (fuel) cost in the objective function was modeled by a set of piecewise } \\
\text { blocks instead of quadratic representation. }\end{array}$ & [17] \\
\hline 1978 & $\begin{array}{l}\text { Solution to UC } \\
\text { problem }\end{array}$ & $\begin{array}{l}\text { Mixed Integer Linear programming (MILP) was applied to formulate and solve the } \\
\text { UC problem for the first time. }\end{array}$ & {$[18]$} \\
\hline \multirow[t]{2}{*}{$1980 \mathrm{~s}$} & Environment of UC & $\begin{array}{l}\text { The electrical energy systems around the world has known important transformations } \\
\text { in different scales, from generation of electricity until consuming it by customer. }\end{array}$ & [19] \\
\hline & SCUC problem & $\begin{array}{l}\text { SCUC formulations including additional constraints like emission, fuel, and } \\
\text { transmission Constraints have been developed. }\end{array}$ & {$[5]$} \\
\hline $\begin{array}{l}1982- \\
1983\end{array}$ & $\begin{array}{l}\text { Solution to UC } \\
\text { problem }\end{array}$ & Branch-and-Bound method is used for solving UC problem. & {$[20],[21]$} \\
\hline \multirow[t]{2}{*}{1984} & \multirow[t]{2}{*}{$\begin{array}{l}\text { Solution to UC } \\
\text { problem }\end{array}$} & $\begin{array}{l}\text { A new approach to scheduling of generation using Dynamic and Linear programming. } \\
\text { The Lambda iteration method and the gradient method are popularly used for } \\
\text { implementing the dispatch for systems comprising thermal units. }\end{array}$ & {$[22]$} \\
\hline & & $\begin{array}{l}\text { A hybrid method comprises Decomposition and Dynamic programming was proposed } \\
\text { for UC problem solution. }\end{array}$ & [23] \\
\hline 1985 & $\begin{array}{l}\text { Solution to UC } \\
\text { problem }\end{array}$ & & {$[24]$} \\
\hline 1987 & $\begin{array}{l}\text { Solution to UC } \\
\text { problem }\end{array}$ & $\begin{array}{l}\text { Dynamic programming was among the first optimization methods the solve UC } \\
\text { problem and has been used extensively ever since. }\end{array}$ & {$[25]$} \\
\hline 1988 & $\begin{array}{l}\text { Solution to UC } \\
\text { problem }\end{array}$ & $\begin{array}{l}\text { An Expert system-based consultant to assist the power system operators in the } \\
\text { planning of the operation of generating units has been proposed. }\end{array}$ & [26] \\
\hline $1990 \mathrm{~s}$ & Environment of UC & $\begin{array}{l}\text { The electricity business is rapidly becoming market-driven. It has moved from a } \\
\text { vertically integrated environment to one that has been horizontally integrated into } \\
\text { which the generation, transmission, and distribution are separated. }\end{array}$ & [27] \\
\hline \multirow{2}{*}{1990} & \multirow{2}{*}{$\begin{array}{l}\text { Solution to UC } \\
\text { problem }\end{array}$} & Many works have chosen Lagrangian relaxation approach for solving UC problem. & \multirow{2}{*}{ [19] } \\
\hline & & Fuzzy system method is used to solve UC problem. & \\
\hline \multirow{4}{*}{$\begin{array}{l}1991- \\
1992\end{array}$} & \multirow{4}{*}{$\begin{array}{l}\text { Solution to UC } \\
\text { problem }\end{array}$} & $\begin{array}{l}\text { Expert system-based approach to short-term UC problem, which is destined to deal } \\
\text { with large generation schedules in real time. }\end{array}$ & {$[28]$} \\
\hline & & New fuzzy dynamic method was presented for UC problem solution. & [19] \\
\hline & & A solution of UC problem by Artificial neural networks is given. & [29] \\
\hline & & A rigorous formulation was proposed to manage the ramp rate limits in UC problem. & [30] \\
\hline
\end{tabular}




\section{4 \\ Formulation of UC problem \\ Solution to UC problem \\ 1995 \\ SCUC problem \\ 1996 \\ Solution to UC problem}

Formulation of UC problem

Stochastic programming to solve UC problem

Solution to UC problem

1998

Solution to UC problem

SCUC with uncertainties

in the power

system

Formulation of UC problem
Integration of RES

A hydrothermal scheduling algorithm was proposed to deal with UC problem in short horizon.

Proposition of rigorous method to deal with security constraints in UC problem. The results show that this method provides better and faster solutions than if security constraints are considered retroactively.

First UC solutions using Tabu search and Genetic algorithms.

Evolutionary programming approach to solve the UC problem.

The production cost is modeled as a piecewise-linear function to facilitate the calculation of global operating cost.

A stochastic approach for UC problem that develops a model and a solution technique for the problem of generating electric power when demands are not certain.

Application of the Particle swarm algorithm using binary variables is proposed to solve UC problem.

An efficient algorithm based on Benders decomposition technique has been presented to address transmission-constrained UC problem.

A Simulated annealing algorithm for UC problem was presented. New rules for randomly generating feasible solutions are also proposed.

The authors presented SCUC program that optimizes the programmed generation and price-sensitive load while satisfying generation, reserve requirements, transmission constraints, and generator operating constraints. formulation for an optimal power flow. The problem is solved by applying Bender decomposition technique.

The Interior point method was proposed to solve scheduling problems in power system.

SCUC with uncertainties is widely being a subject of research by the authors.

The barriers to RES penetration in power system was discussed. Several works treat the Integration of renewable energy in the power system and its impact.

The authors proposed an extension of The MILP formulation to model the selfscheduling problem faced by a single generating unit in an electricity market.

A MILP formulation for the stair wise start-up cost was proposed

2001- Solution to UC problem

Solution to UC problem

2003 Solution to UC problem

2004 Formulation of UC problem

Solution to UC problem

2005

Solving UC problem using Ant colony search algorithm.

A solution of UC problem is given by multi-agent modeling.

Hybrid particle swarm method was proposed to deal with UC problem. solution of the UC problem.

A solution to PBUC problem is given by using multi-agent modeling.

Proposition of an efficient SCUC approach with alternative current constraints that obtains the minimum operating cost while maintaining the security of power systems.

Formulation of the PBUC problem based on MIP method. The PBUC MIP solution

Formulation of UC was compared with that of Lagrangian relaxation method.

The first 1-bin UC formulation was presented. The new formulation eliminates two 
2006

2007

2008

Uncertainty UC

Uncertainty UC

Stochastic programming to

Formulation of UC problem

Stochastic

programming to solve UC problem

Formulation of UC problem sets of binary variables from the 3-bin model.

Many works have studied the RES impact on future power system.

The authors compared an Advanced Priority Listing method with a MILP approach for solving the UC problem.

New formulation of short-term electricity market compensation with stochastic security, taking into account the undistributed and variable sources of wind generation.

Application of stochastic methods in electricity markets to ensure reliable power system operations.

A new hybrid meta-heuristic method has been proposed to deal with UC problem, including Tabu search and Evolutionary particle swarm optimization.

A proposal for a new way to construct approximate MILP formulations for the hydrothermal UC problem.

Two UC methods have been proposed to address the variability and irregularity of wind energy. Many scenarios in the UC stochastic approach capture the uncertainty of wind energy, while a predictive value of wind energy production was used in the deterministic case.

The authors proposed a methodology for determining the required level of spinning and non-spinning reserves in an electrical system with a strong penetration of wind energy.

The comparison between stochastic and reserve methods was proposed and then, the authors evaluated the advantages of a combined approach to the effective management of disturbances in the UC problem.

Numerous stochastic programming models for optimal decision making under uncertainty in power systems have been proposed.

The authors examined two modeling approaches for reducing the computational cos of stochastic UC: relaxation of the integrity constraint of fast start-units and modeling of generation failures as load increments.

Incorporation of PV and wind units in power systems has been studied and a riskconstrained solution to this problem was given.

The hardness of wind power forecasting (WPF) in UC problem was discussed. In deterministic approaches, a forecast value of wind generation is indicated. In contrary, a number of scenarios captures WPF uncertainty in the stochastic UC.

Tight MILP formulation for the UC problem using 3 binary variables was proposed.

Representation of UC problem with uncertain generation from wind units is given The problem has been formulated as a chance-constrained two-stage stochastic program.

Start-up and shutdown power trajectories of thermal generators was formulated using MILP.

The authors presented a complete quadratic programming formulation of the thermal UC problem as well as a new iterative optimization algorithm for its solution.

A study of stochastic UC problem with uncertain demand response to increase the reliability of UC process for ISOs.

Multi-agent modeling is used for simulating and solving profit based UC problem

The authors provided a UC-based market clearing formulation, clearly distinguishing between power and energy. The model was formulated as MIP problem.

The impacts of intermittent RES on the large-scale power system was quantified Moreover, a discussion on how to model RES effects on a low-carbon power system was presented.

The researchers provided various methodologies and software tools developed for optimal short-term scheduling considering the stochastic nature of the various system 
2014

solve UC problem
Solution to UC problem

Formulation of UC problem

2015- Integration of RES

2016
Integration of RES
in the power system

and unit parameters, such as the system load, RES production, and unit availability.

The researchers addressed the problem of decision making in operation power systems with a significant penetration of wind power.

Transmission-constrained UC formulation that ameliorates the performance of the interval UC was proposed.

In the context of day-ahead and intra-day UC under wind uncertainty, a comparison between two-stage and multi-stage stochastic models was suggested.

Many works review the state-of-the-art of solution methodologies for a deterministic SCUC and extend the results to the solution of stochastic SCUC for effectively managing uncertainties and enhancing the reliability of power system operations.
[75]

\section{Stochastic programming to solve UC problem}

SCUC with uncertainties

\section{Formulation of UC problem \\ Integration of RES in the power system}

Solution to UC problem

Solution to UC problem
A novel two-binary-variable (2bin) MIP formulation for the UC problem is proposed.

The energy-water nexus literature has shown that the electricity \& water infrastructure that allows the production, distribution, and consumption of these two valuable products is complicated. The proposed paper builds upon this foundation with the development of the corresponding UC problem.

The authors proposed a solution of UC problem based on Ant lion optimizer in the cases of conventional UC and smart grid.

Grey wolf optimization algorithm is used to solve the wind generator integrated UC problem.

\section{UC PROBLEM FORMULATION}

Mathematically, UC problem has been formulated as a non-convex, large-scale, non-linear, and MIP combinatorial optimization problem with constraints [10], [51], [66]. The non-convexity is caused by the binary nature of UC decision (ON/OFF). Non-linearity happens due to non-linear generation cost curves and non-linear transmission constraints. The existence of a combination of the binary and non-linear variables requires the problem to be formulated as a MIP problem [72]. The mathematical formulation for the problem is analytically described in the following paragraphs.

\subsection{Deterministic formulation of unit commitment problem}

The deterministic formulation of the UC problems can be considered as a special case of the respective stochastic formulation, where only a single scenario comprising the forecast values of the random unit and system parameters is considered [6]. The MILP approach has been proposed since the 1970s as a practicable and efficient alternative methodology for solving various optimization problems related to shortterm operation of electrical systems, in particular UC problem [8]. In fact, most researches in this field have recognized that critical decisions associated with the operation of the power system can be effectively represented by integer (binary in general) variables and, therefore, classical linear programming approaches are not able to clearly model and solve such complicated problems. In MILP formulations, the commitment 
decisions indicating the ON/OFF status of the generating units in various operating phases (offline, start-up, dispatch, and shutdown) are modeled using binary variables, while the power output, reserve contribution, and flow decisions are represented using continuous variables [8].

\subsubsection{Mixed integer linear programming formulation}

The MILP formulation revisited in this paper is based on a single binary variable to describe the UC status and the corresponding hourly transition of generating units. Alternatively, a three-binary-variable formulation, considering UC status and start-up/shutdown indicators has been proposed in several works [68], [71].

The MILP deterministic UC problem can be formulated as [19], [27]:

$$
\mathrm{OC}=\sum_{i=1}^{N} \sum_{t=1}^{T} F C_{i t}\left(P_{i t}\right) I_{i t}+N L_{i} I_{i t}+S T_{i t}+S D_{i t}
$$

Where $\mathrm{OC}$ is the operating cost, $\mathrm{N}$ is the number of generating units, $\mathrm{T}$ is the time horizon, which is $24 \mathrm{~h}$, and $I_{i t}$ is a binary variable modeling UC decision of unit $i$ at hour $t$.

$F C_{i t}\left(P_{i t}\right)$ is the fuel cost, $N L_{i}$ is the no-load cost of unit $i, S T_{i t}$ and $S D_{i t}$ are respectively the start-up and shutdown costs of unit $i$ at hour $t$.

$F C_{i t}\left(P_{i t}\right)$ is the input/output curve that is modeled with a quadratic function of the power output [36], [71]:

$F C_{i t}\left(P_{i t}\right)=a_{i} P_{i t}^{2}+b_{i} P_{i t}+c_{i}$

$a_{i}, b_{i}$ and $c_{i}$ are the cost coefficients.

Practically this cost is modeled as a piecewise-linear function [36], [71]. A tight formulation for this piecewise-linear approximation is given in [60].

$S T_{i t}$ is the cost for restarting a de-committed thermal unit, which is depended to the temperature of the boiler. The number of the start-up and shutdown and their type (hot or cold) changes in function of the ON/OFF status of the units [3]. It is expressed as follows [66], [83]:

$$
S T_{i t}= \begin{cases}H S N_{i}, & \text { if } \quad M D T_{i} \leq T_{\text {off } f,}(t) \leq M D T_{i}+T_{\text {cold }, i} \\ C S N_{i}, & \text { if } \quad T_{\text {off. }}(t)>M D T_{i}+T_{\text {cold. } i}\end{cases}
$$

Where $H S N_{i}$ and $C S N_{i}$ are respectively the hot and cold start-up cost of unit $i . M D T_{i}$ is the minimum downtime of unit $i . T_{o f f, i}$ is the continuous offline period of unit $i$ at hour $t . T_{c o l d, i}$ is the cold start hour of unit $i$.

The shutdown costs $S D_{i t}$ are usually neglected and have been taken to be equal to zero for all units [3], [72].

\subsubsection{Unit commitment constraints}

In minimizing OC, the UC problem solution must respect both generator physical constraints and system operational constraints [27], [66]. These constraints can be one or more of the following types:

a. Generating limits constraints

Each generating unit has minimum and maximum limits. The power output cannot exceed these limits [19], [51], [72]:

$$
P_{i t}(\min )<P_{i t}<P_{i t}(\max )
$$

Where $P_{i t}(\mathrm{~min})$ and $P_{i t}(\max )$ are respectively the minimum and maximum real power output of unit $i$ at hour $t$.

b. Power balance constraint

The equilibrium between load demand and power output in each hour is given by [3], [66], [72]:

$$
\sum_{i=1}^{N} P_{i(\max )}(t) \cdot I_{i}(t)=D_{t}
$$

Where $D_{t}$ is the total demand at hour $t$.

c. Minimum up /down time constraints

Minimum up-time is the minimum number of hours of operation at or above the minimum generation capacity. It is expressed as follows [3], [66]:

$$
T_{i}^{o n}>M U T_{i}
$$


Where $T_{i}^{o n}$ and $M U T_{i}$ are the total up-time and the minimum up-time of unit $i$.

Minimum downtime is the minimum number of hours once the generator is shutdown before it can be brought online again to generate power [3], [66]:

$$
T_{i}^{o f f}>M D T_{i}
$$

Where $T_{i}^{\text {off }}$ and $M D T_{i}$ are the total downtime and the minimum downtime of unit $i$.

d. Ramp rate up/down constraints

The generator power output is not changing instantaneously. Its variation depends on ramp rate limits. These constraints are formulated based as on the following conditions [3], [51], [72]:

$$
\begin{aligned}
& P_{i, t}-P_{i, t-1} \leq U R_{i} \\
& P_{i, t-1}-P_{i, t} \leq D R_{i}
\end{aligned}
$$

Where $U R_{i}$ and $D R_{i}$ are the ramping up and ramping down of unit $i$.

e. Spinning reserves constraint

Spinning reserve is an indicator of the amount of power that is required to fulfill percentage of forecasted peak demand or capable of making up the loss of the most important loaded unit in each time. The formulation for spinning reserve can be expressed as [3], [51], [66]:

$$
\sum_{i}^{N}\left(I_{i t} . P_{i t}\right) \geq\left(D_{t}+R_{t}\right), \quad 1 \leq t \leq T
$$

Where $R_{t}$ is the spinning reserve at hour $t$.

f. Must run and must out units

The must run units are a prescheduled unit which must be online, due to operating reliability or economic purposes. The RES units are necessary run units for better economic system operation. Must out units are the units unavailable for commitment because of forced outages or maintenance interventions [19].

g. Transmission constraints

Transmission constraints are to satisfy customer load demands and maintain transmission flows and bus voltages within admissible limits [84]. Generally, linear DC (direct current) transmission constraints are integrated in UC problem formulation for system security considerations [4].

h. Crew constraints

In a plant with many units, there may not be enough personnel to attend both the units if both are starting up and/or shutting down simultaneously. Such constraints would be set by the times required to startup and to shutdown the unit [19].

\subsection{Unit commitment in deregulated environment}

Since 1980s, Power systems have moved from a vertically integrated structure to a deregulated one. In an integrated environment, customers of generation companies (GENCOs) are already set and defined [5]. In the case of deregulated markets, components of electricity market such as generation companies (GENCOs), transmission companies (TRANSCOs), and distribution companies (DISCOs), construct their generation offers based on available signals, and consequently getting UC solution. Each offer consists of a cost function and a set of parameters that define the operative constraints of generating units, which enables to determine the system marginal cost for each period [84]. In deregulated environment, the objective changes from cost minimization to profit maximization [19]. The studies in [85], [86] presented a new formulation of the UC problem in a deregulated market.

\subsection{Price-based unit commitment}

In PBUC, satisfying hourly load is no longer a restriction and the objective is to maximize the profit while security is now unrestrained from energy and considered as ancillary service. Thus, in the PBUC approach, the signal that would determine a unit's commitment status is the price of different services and materials in electrical operations such as fuel purchase price, energy sale price, and ancillary service sale price [54], [84]. The energy suppliers are responsible for the way they sell energy in order to supply load and reserve markets [4]. The most distinct characteristic of PBUC is that all market information are expressed in market price. PBUC problem formulations are given in [4], [54]. 


\section{STOCHASTIC PROGRAMMING'S APPLICATION IN UNIT COMMITMENT}

Nowadays, the growing capacity for renewable generation such wind and solar units has strongly augmented the levels of variability and uncertainty in the system, making the ideal UC model a large-scale, non-convex, uncertain program [87]. The integration of RES into the power system despite its intermittent nature is mainly justified by its economic and environmental benefits for the system. Sources of uncertainty present in real operational environments are [87]: load demand, renewable generation, unit availability, inflows for the hydro reservoirs, and energy prices. Generally, forecast errors mainly result from load variations. However, the increased penetration of RES lead to supplemental generation forecast errors due to its intermittence [5]. Stochastic programming offers modeling and solution techniques for such optimization problems under uncertainty [46]. Actually, to achieve minimum OC subject to power balance constraints, SOs first determine generating units ON/OFF statuses and production capacities based on forecast values and technical constraints of each unit. Afterwards, a re-dispatch is carried out in real-time to adjust the difference between the real demand and expected output. Therefore, UC is a multi-stage decision process like stochastic programming (SP)'s solving procedure, which justifies the implementation of SP for solving UC problem with uncertainties [5].

\subsection{Two-stage stochastic programming formulation for unit commitment}

The basic UC formulation (without considering security constraints) serves as the support for SP's implementation in UC problem. Two-stage SP is a commonly used approach to capturing uncertainty, and it has the following form [5]:

$$
\operatorname{Min} c^{T} x+E[Q(x, \xi)], \text { s.t. } A x=b, x \geq 0
$$

Where

$$
Q(x, \xi)=\min \{q y(\xi), W y(\xi)=h-T x, y(\xi) \geq 0\}
$$

Here, $x$ and $y(\xi)$ denote the first-stage and second-stage decision variables respectively. Mainly, variables $x$ represent the decisions that must be taken before the uncertainty is solved, and the function $Q(x, \xi)$ represent the decisions that can be taken after the uncertainty is solved. The $\xi$ in the second-stage is a random vector and $E[Q(x, \xi)]$ is used to return the cost related to this random vector's consequences to the objective function.

\subsection{Security constrained unit commitment}

The fundamental concept in the reliable and economic operation of electric power systems is SCUC. SCUC refers to the economic scheduling of generating units to meet the hourly load demand while satisfying temporal and operational limits of generation and transmission equipment in contingency power systems [27]. In a vertically integrated environment, SOs apply SCUC for minimizing the OC while meeting the system load by starting up/shutting down generating units. In restructured power markets, SCUC is utilized by ISOs to lighten real time and day-ahead markets, with the objective of maximizing the social welfare based on offers and bids submitted by market participants. The SCUC models and solution methodologies is an important key decision-making component in power system operations, particularly for large systems. Mathematically, the SCUC problem is a large-scale MIP problem with many binary, continuous and discrete control variables, and a series of constraints [4]. SCUC approach with AC constraints is proposed in [53]. In [45], a SCUC model for open market, which optimizes the operation scheduling and price-sensitive load is presented. The proposed model satisfy generation, reserve requirements, transmission and operating constraints. Detailed formulation of deterministic SCUC problem is proposed in [27].

\subsection{Security constrained unit commitment with uncertainties}

There are at least three solution techniques that have been proposed for managing uncertainties in SCUC, including stochastic programming (SP), robust optimization (RO), and chance-constrained optimization $(\mathrm{CCO})$. Each technique has different practical and computational requirements for representing and limiting the uncertainties in power system [87]. SCUC problem with uncertainties is a large-scale, nonconvex, NP-hard problem with difficult solution [27]. Therefore, in the three models, the original large-scale MIP problem is usually decomposed to a master problem and many subproblems by Benders decomposition technique [61]. The next paragraphs briefly discuss the three methodologies proposed in literature. 


\subsubsection{Stochastic programming}

SP is a renowned optimization technique to solve SCUC problem with uncertainties. In the SP approach, power system uncertainties are represented by a set of scenarios for the possible realization of different uncertainties [6].SP technique is based on scenario tree in which uncertainty is supposed to be known in its each node since furthermore uncertainty is now discretized on the tree, essentially the quantity for solving a deterministic large-scale UC problem [87].Usually, the scenario-based approach generates scenarios via assumed probability distribution functions for simulating uncertainties and each scenario is attributed a certain probability for its realization. In SP, many scenarios are needed for reaching an acceptable solution, which rises the size of the model, extends the computation burden, and limits the application to large size power systems. Thus, the scenario reduction techniques are usually adopted to reduce the scale of the stochastic model and the required computation effort, which enables to keep close scenarios by measuring the probabilistic distance between scenarios and eliminates scenarios with very low probabilities [27].

\subsubsection{Robust optimization}

$\mathrm{RO}$ is an alternative technique for dealing with uncertainties in the SCUC problem. RO uses the notion of uncertainty set be less demanding on the representation of uncertainty, which assembles the adverse events against which we wish to protect ourselves. This uncertainty set considers a limited level of information on uncertain quantities, namely the mean value and some estimate of the variance or a range of possible variations around the mean [27].Consequently, the RO model seeks an optimal commitment and dispatch solution of the generating units for preventing the solution against the worst economic condition (the highest minimum dispatch cost), which would protect the power system against each event in the specified uncertainty set regardless of its probability [87].

\subsubsection{Chance-constrained optimization}

CCO is another applicable approach for handling uncertainties in the hourly SCUC problem, in which temporal constraints can be violated with a predefined level of probability. CCO appears as a good alternative to select the tradeoff between cost and robustness based on the probability that the selected solution is the feasible one which is easy for SO to understand and manage [87]. CCO matches the nature of the SCUC operation that one may not actually be able to guarantee that transmission security constraints (such as system load balance or transmission capacity) will never be violated. Rather, one should provide SCUC solutions that are reasonably feasible by offering limited load shedding, under all except the most unlikely scenarios [27].

\subsubsection{Comparison of solution approaches}

The three SCUC formulations with uncertainties may represent different performances, including solution robustness in the face of uncertainties, the cost of generation schedules, and the computational cost. The proposed techniques may be effectively combined for enhancing the quality of the SCUC solution and augmenting the computational performance of the proposed heuristics [27]. In this context, work in [69] presented UC problem with uncertain wind generation. The proposed model includes both the two-stage stochastic program and the chance-constrained stochastic program techniques, which has allowed getting a good quality solution. Table 2 provides a comparison between the three solution techniques presented in this section.

Table 2. Comparison between SolutionAapproaches for dealing with Uncertainties Inspired from [27]

\begin{tabular}{|c|c|c|c|}
\hline $\begin{array}{l}\text { Solution } \\
\text { technique }\end{array}$ & Uncertainty representation & Features & Limits \\
\hline SP & $\begin{array}{l}\text { Set of scenarios for the possible } \\
\text { realization of various } \\
\text { uncertainties. }\end{array}$ & $\begin{array}{l}\text { 1. Uncertainty is supposed to be known in } \\
\text { each node of the tree. } \\
\text { 2. It could consider the anticipated } \\
\text { reactions of SO in real time through the } \\
\text { second-stage scenario-dependent } \\
\text { formulation. }\end{array}$ & $\begin{array}{l}\text { 1. The quality of solutions could } \\
\text { critically depend on the choice of the } \\
\text { scenario set. } \\
\text { 2. Achieving an accurate probability } \\
\text { distribution can be complicated. } \\
\text { 3. The solutions offer only probabilistic } \\
\text { guarantees. }\end{array}$ \\
\hline RO & $\begin{array}{l}\text { Relegation of explicit knowledge } \\
\text { on probability distributions and } \\
\text { scenario samplings by using a } \\
\text { deterministic uncertainty set. }\end{array}$ & $\begin{array}{l}\text { 1. It does not require an explicit } \\
\text { knowledge of probability distributions. } \\
\text { 2. The approach would protect the system } \\
\text { against every possible realization of } \\
\text { uncertainties contained in the chosen set. }\end{array}$ & $\begin{array}{l}\text { 1. Uncertainty intervals should be } \\
\text { carefully selected and the budget level } \\
\text { would need to be neatly tuned. }\end{array}$ \\
\hline
\end{tabular}




\begin{tabular}{|c|c|c|c|}
\hline $\begin{array}{l}\text { Solution } \\
\text { technique }\end{array}$ & Uncertainty representation & Features & Limits \\
\hline $\mathrm{CCO}$ & $\begin{array}{l}\text { Sampling scenarios to approach } \\
\text { the real distribution of random } \\
\text { variables or converting to a } \\
\text { sequence of deterministic } \\
\text { equivalents. }\end{array}$ & $\begin{array}{l}\text { 1. The solution is independent of the } \\
\text { choice of scenarios. } \\
\text { 2. More robust solutions than those of the } \\
\text { SP-based SCUC. }\end{array}$ & $\begin{array}{l}\text { 1. It requires an explicit knowledge of } \\
\text { the probability distribution of } \\
\text { uncertainties. } \\
\text { 2. CCO-based SCUC models are usually } \\
\text { more difficult to solve than the SP-based } \\
\text { SCUC models. }\end{array}$ \\
\hline
\end{tabular}

\section{OPTIMIZATION TECHNIQUES FROM CLASSICAL TO HYBRID METAHEURISTIC}

Various approaches for solving UC problem have been proposed, where they extended from simple to hybrid metaheuristic methods [72]. The UC problem is among the tough problems in electricity market [2]. Several mathematical techniques have been proposed for solving this time-dependent problem. A popular method for UC problem solution in the past has been Lagrangian relaxation [54], [68]. In [87], the UC methodologies have been classified in four categories: dynamic programming, MILP approaches, decomposition approaches and metaheuristics approaches. The study in [4] differenced the optimization techniques in deterministic techniques and metaheuristics techniques. In recent years, meta-heuristics approaches have been widely used for UC problem solution because of their capability to handle large-scale problems. Generally, the hybrid methods such as Memetic algorithms and Hybrid ant colony optimization have better quality solutions. It has been mentioned that the combined use of the Lagrangian relaxation and Memetic algorithms provides the best result for the UC problem [4]. The choice of convenable method depends on the types of units present in power plant and their technical constraints. A comprehensive review of different methods used in the UC problem-solving technique is presented in Table 3. Otherwise, recently multi-agent systems (MAS) are presented as a powerful tool to simulate and solve different problems in electrical energy systems such as UC problem. MAS are a grouping of entities (or agents) that interact with each other to get a collective goal. MAS give a simple and real representation of complex problems by representing components of the system and their interactions on physical and software agents. In this context, works in [49], [52], [74] presented applications of MAS to solve UC problem.

Table 3. Comparison of Optimization Techniques for Solving UC Problem

\begin{tabular}{cll}
\hline Method & \multicolumn{1}{c}{ Advantages } & \multicolumn{1}{c}{ Weakness } \\
\hline $\begin{array}{c}\text { Priority } \\
\text { List }\end{array}$ & Simplest and fastest method to solve UC problem. & $\begin{array}{l}\text { The solution is far from the optimal. } \\
\text { Weak final solution. }\end{array}$ \\
$\begin{array}{c}\text { Dynamic } \\
\begin{array}{c}\text { Programmi } \\
\text { ng }\end{array}\end{array}$ & $\begin{array}{l}\text { Ability to manage sub-problems in decomposition } \\
\text { programs and maintain the solution feasibility. }\end{array}$ & $\begin{array}{l}\text { It requires limiting the commitments considered } \\
\text { at any time. } \\
\text { It suffers from imprecation of dimensionality. }\end{array}$
\end{tabular}

Lagrangian Relaxation

It is able to process with ramp rate, fuel and emission constraints only by relaxing them.

It can be employed to further decompose subproblems.
It suffers from existence of duality gap.

It finds a problem to solve the original problem

of non-convex programs.

Benders It allows separating the problem into independent Low speed of convergence.

Decomposit easy ones.

ion It decomposes the global problem into a master

problem and many subproblems.

Interior It converges rapidly towards the optimal solution.

Point It deals nicely with parameter setting.

Slow speed while searching the optimal solution

The optimal decision secures the minimum $\mathrm{OC}$ in a predicted value.

The computational costs increase significantly

ng

Quadratic

It solves UC problem and economic load dispatch with respect to a deterministic formulation.

It requires a long time to find the solution.

Programmi together.

It finds difficulties to solve large-scale system. 


\begin{tabular}{|c|c|c|c|}
\hline Method & Advantages & Weakness & References \\
\hline $\begin{array}{l}\text { Mixed } \\
\text { Integer } \\
\text { Linear } \\
\text { Programmi } \\
\text { ng }\end{array}$ & $\begin{array}{l}\text { Powerful modeling tool. } \\
\text { Ability to reach a globally optimal solution. }\end{array}$ & $\begin{array}{l}\text { It takes a long time compared to fast methods } \\
\text { like heuristics. } \\
\text { Poor efficiency in treating large-scale problems. }\end{array}$ & [93] \\
\hline $\begin{array}{l}\text { branch-and- } \\
\text { bound }\end{array}$ & $\begin{array}{l}\text { It finds an optimal solution if the problem is of } \\
\text { limited size. }\end{array}$ & $\begin{array}{l}\text { The execution time grows exponentially for } \\
\text { large systems. }\end{array}$ & [94] \\
\hline $\begin{array}{l}\text { Non-linear } \\
\text { Programmi } \\
\quad \text { ng }\end{array}$ & $\begin{array}{l}\text { Accurate modelization of power generation } \\
\text { characteristics. }\end{array}$ & $\begin{array}{l}\text { It enhances the problem dimension and } \\
\text { complexity. }\end{array}$ & [95] \\
\hline $\begin{array}{l}\text { Artificial } \\
\text { Neural } \\
\text { Network }\end{array}$ & $\begin{array}{l}\text { Capable of dealing with the stochastic variation of the } \\
\text { scheduled operation point with increasing data. } \\
\text { Flexibility with noisy data. }\end{array}$ & $\begin{array}{l}\text { The computation time augments exponentially } \\
\text { with large size problems. }\end{array}$ & [96] \\
\hline $\begin{array}{l}\text { Simulated } \\
\text { Annealing }\end{array}$ & $\begin{array}{l}\text { It can be readily coded, even for NP-hard problems } \\
\text { such as UC. } \\
\text { Starting with any initial solution, the algorithm will } \\
\text { attempt to get an improved solution. }\end{array}$ & $\begin{array}{l}\text { Its takes long time to find a near optimal } \\
\text { solution. } \\
\text { The method cannot tell that an optimal solution } \\
\text { is found. }\end{array}$ & [97] \\
\hline $\begin{array}{l}\text { Genetic } \\
\text { Algorithm }\end{array}$ & $\begin{array}{l}\text { It solves the problem with multiple solutions. } \\
\text { The structural genetic algorithm has the ability to } \\
\text { solve the solution structure and solution parameter } \\
\text { problems simultaneously. }\end{array}$ & $\begin{array}{l}\text { No guarantee that a genetic algorithm will find a } \\
\text { global optimal solution. } \\
\text { High execution time. }\end{array}$ & [98] \\
\hline $\begin{array}{l}\text { Evolutionar } \\
\text { y } \\
\text { Programmi } \\
\text { ng }\end{array}$ & $\begin{array}{l}\text { They are robust with respect to noise evaluation } \\
\text { functions. } \\
\text { It can handle higher dimensional problems. }\end{array}$ & Generally, it does not give the global extremum. & [99] \\
\hline $\begin{array}{c}\text { Tabu } \\
\text { Search }\end{array}$ & $\begin{array}{l}\text { It is one of general optimization methods, the cost } \\
\text { function has no limitations. } \\
\text { Its adaptive memory allows creating a more flexible } \\
\text { search behavior. }\end{array}$ & $\begin{array}{l}\text { It can be blocked in a local optimum, without a } \\
\text { possibility of exploring other regions of the } \\
\text { solution space. }\end{array}$ & {$[100]$} \\
\hline Ant Colony & $\begin{array}{l}\text { Rapid discovery towards good solutions. } \\
\text { Capable of handling large-scale problems like UC } \\
\text { problem. }\end{array}$ & $\begin{array}{l}\text { Theoretical analysis is difficult. } \\
\text { Probability distribution changes by iteration. }\end{array}$ & [101] \\
\hline $\begin{array}{l}\text { Particle } \\
\text { Swarm } \\
\text { Optimizatio } \\
\text { n }\end{array}$ & $\begin{array}{l}\text { Robust to solve problems featuring non-linearity and } \\
\text { non-differentiability. } \\
\text { Fast convergence speed. } \\
\text { It does not need a lot of parameter to tune. } \\
\text { An easy search in complex problems with large set of } \\
\text { variables. }\end{array}$ & Slow convergence in local search. & [102] \\
\hline Fire Fly & $\begin{array}{l}\text { Easy to understand and code. } \\
\text { It is a suitable method for environmental and } \\
\text { economic dispatch problem. }\end{array}$ & Slow convergence speed. & {$[103]$} \\
\hline $\begin{array}{l}\text { Fuzzy } \\
\text { Logic }\end{array}$ & $\begin{array}{l}\text { It gives a qualitative description of the behavior of a } \\
\text { system, and its characteristics. } \\
\text { Capability to handle any type of unit characteristics } \\
\text { data. }\end{array}$ & $\begin{array}{l}\text { It cannot handle large-scale system. } \\
\text { It suffers from complexity. }\end{array}$ & [104] \\
\hline $\begin{array}{l}\text { Expert } \\
\text { Systems }\end{array}$ & $\begin{array}{l}\text { The knowledge base can be updated and extended. } \\
\text { They can contain a large amount of information. } \\
\text { They reduce the time taken to solve the problem. }\end{array}$ & $\begin{array}{l}\text { It finds a problem if the new generating schedule } \\
\text { is different from the system schedules. } \\
\text { They cannot creatively come with new solutions } \\
\text { for the issues. }\end{array}$ & [105] \\
\hline $\begin{array}{l}\text { Hybrid } \\
\text { Meta- } \\
\text { Heuristic }\end{array}$ & $\begin{array}{l}\text { It is capable to escaping from a local solution. } \\
\text { Capable of handling indifferentiable cost functions } \\
\text { and constraints. }\end{array}$ & Its main negative point is fine-tuning. & [106] \\
\hline
\end{tabular}




\section{CONCLUSION}

This paper provides a comprehensive review of UC problem, based on articles and works published since 1959until now. The historical events, UC problem formulations, and techniques for solving it are all reviewed. Many review articles have been presented in the previous years, most of them have given a review of optimization techniques for solving UC problem but no paper has provided a global stat of the art of the problem with its different aspects. To this end, Table 1 provides the remarkable researches and studies in the field of UC problem through the years. In addition, Table 3 summarizes the optimization techniques for solving the problem in the deterministic case and under uncertainty. The researchers are always interested in working in this field, particularly with the massive incorporation of renewable energy into the power system.

\section{REFERENCES}

[1] A. Bhardwaj, et al., "Unit commitment in electrical power system-a literature review," Power Engineering and Optimization Conference (PEDCO) Melaka, Malaysia, 2012 Ieee International, pp. 275-280, 2012.

[2] M. S. Pinto, et al., "Risk and unit commitment decisions in scenarios of wind power uncertainty," Renewable Energy, vol. 97, pp. 550-558.

[3] S. Y. Abujarad, et al., "Recent approaches of unit commitment in the presence of intermittent renewable energy resources: A review," Renewable and Sustainable Energy Reviews, vol. 70, pp. 215-223, 2017.

[4] H. Y. Yamin, "Review on methods of generation scheduling in electric power systems," Electric Power Systems Research, vol. 69, no. 2, pp. 227-248, 2004.

[5] H. Dai, et al., "A literature review of stochastic programming and unit commitment," Journal of Power and Energy Engineering, vol. 3, no. 4, pp. 206, 2015.

[6] J. P. Catalão, "Smart and sustainable power systems: operations, planning, and economics of insular electricity grids," CRC Press, 2015.

[7] P. S. Georgilakis, "Technical challenges associated with the integration of wind power into power systems," Renewable and Sustainable Energy Reviews, vol/issue: 12(3), pp. 852-863, 2008.

[8] C. A. Li, et al., "A new unit commitment method," IEEE Transactions on Power Systems, vol. 12, no. 1, pp. 113-119, 1997.

[9] C. L. Tseng, "On power system generation unit commitment problems," University of California, Berkeley, 1996.

[10] M. Carrión and J. M. Arroyo, "A computationally efficient mixed-integer linear formulation for the thermal unit commitment problem," IEEE Transactions on power systems, vol. 21, no. 3, pp. 1371-1378, 2006.

[11] C. J. Baldwin, et al., "A study of the economic shutdown of generating units in daily dispatch," Transactions of the American Institute of Electrical Engineers, Part III: Power Apparatus and Systems, vol. 78, no. 4, pp. 1272-1282, 1959.

[12] L. L. Garver, "Power generation scheduling by integer programming-development of theory," Transactions of the American Institute of Electrical Engineers. Part III: Power Apparatus and Systems, vol. 81, no. 3, pp. 730-734, 1962.

[13] K. Hara, et al., "A method for planning economic unit commitment and maintenance of thermal power systems," IEEE Transactions on Power Apparatus and Systems, vol. 5, pp. 427-436, 1966.

[14] R. M. Burns and C. A. Gibson, "Optimization of priority lists for a unit commitment program," in IEEE Transactions on Power Apparatus and Systems, 345 E 47th St, New York, Ny 10017-2394: IEEE-Inst Electrical Electronics Engineers Inc., vol. 94, no. 6, pp. 1917- 1917, 1975.

[15] J. A. Muckstadt and S. A. Koenig, "An application of Lagrangian relaxation to scheduling in power-generation systems," Operations research, vol. 25, no. 3, pp. 387-403, 1977.

[16] R. Wiebking, "Stochastische Modelle zur optimalen Lastverteilung in einem Kraftwerksverbund," Mathematical Methods of Operations Research, vol. 21, no. 6, pp. B197-B217, 1977.

[17] S. Bradley, et al., "Applied mathematical programming," 1977.

[18] T. S. Dillon, et al., "Integer programming approach to the problem of optimal unit commitment with probabilistic reserve determination," IEEE Transactions on Power Apparatus and Systems, vol. 6, pp. 2154-2166, 1978.

[19] N. P. Padhy, "Unit commitment-a bibliographical survey," IEEE Transactions on power systems, vol. 19, no. 2, pp. 1196-1205, 2004.

[20] G. S. Lauer, et al., "Solution of large-scale optimal unit commitment problems," IEEE Transactions on Power Apparatus and Systems, vol. 1, pp. 79-86, 1982.

[21] A. I. Cohen and M. Yoshimura, "A branch-and-bound algorithm for unit commitment," IEEE Transactions on Power Apparatus and Systems, vol. 2, pp. 444-451, 1983.

[22] H. P. V. Meeteren, "Scheduling of generation and allocation of fuel, using dynamic and linear programming," IEEE transactions on power apparatus and systems, vol. 7, pp. 1562-1568, 1984. 
[23] A. J. Wood and B. F. Wollenberg, "Power generation, control, and operation," 1984.

[24] P. P. J. V. den Bosch and G. Honderd, "A solution of the unit commitment problem via decomposition and dynamic programming," IEEE Transactions on Power Apparatus and Systems, vol. 7, pp. 1684-1690, 1985.

[25] W. L. Snyder, et al., "Dynamic programming approach to unit commitment," IEEE Transactions on Power Systems, vol. 2, no. 2, pp. 339-348, 1987.

[26] S. Mokhtari, et al., "A unit commitment expert system (power system control)," IEEE Transactions on Power Systems, vol. 3, no. 1, pp. 272-277, 1988.

[27] L. Wu and M. Shahidehpour, "Security-Constrained Unit Commitment with Uncertainties," Power Grid Operation in a Market Environment: Economic Efficiency and Risk Mitigation, pp. 115-168, 2016.

[28] S. K. Tong and S. M. Shahidehpour, "Hydrothermal unit commitment with probabilistic constraints using segmentation method," IEEE Transactions on Power Systems, vol. 5, no. 1, pp. 276-282, 1990.

[29] C. C. Su and Y. Y. Hsu, "Fuzzy dynamic programming: an application to unit commitment," IEEE transactions on power systems, vol. 6, no. 3, pp. 1231-1237, 1991.

[30] H. Sasaki, et al., "A solution method of unit commitment by artificial neural networks," IEEE Transactions on Power Systems, vol. 7, no. 3, pp. 974-981, 1992.

[31] C. Wang and S. M. Shahidehpour, "Ramp-rate limits in unit commitment and economic dispatch incorporating rotor fatigue effect," IEEE Transactions on Power Systems, vol. 9, no. 3, pp. 1539-1545, 1994.

[32] K. P. Wong and Y. W. Wong, "Short-term hydrothermal scheduling part. I. Simulated annealing approach," IEE Proceedings-Generation, Transmission and Distribution, vol. 141, no. 5, pp. 497-501, 1994.

[33] J. J. Shaw, "A direct method for security-constrained unit commitment," IEEE transactions on power systems, vol. 10, no. 3, pp. 1329-1342, 1995.

[34] H. Mori and T. Usami, "Unit commitment using tabu search with restricted neighborhood," in Intelligent Systems Applications to Power Systems, 1996, Proceedings, ISAP'96, International Conference on, pp. 422-427, 1996.

[35] S. A. Kazarlis, et al., "A genetic algorithm solution to the unit commitment problem," IEEE transactions on power systems, vol. 11, no. 1, pp. 83-92, 1996.

[36] A. J. Wood and B. Wollenberg, "Power generation operation and control-2nd edition," in Fuel and Energy Abstracts, vol. 37, no. 3, pp. 195, 1996.

[37] S. Takriti, et al., "A stochastic model for the unit commitment problem," IEEE Transactions on Power Systems, vol. 11, no. 3, pp. 1497-1508, 1996.

[38] J. Kennedy and R. C. Eberhart, "A discrete binary version of the particle swarm algorithm," in Systems, Man, and Cybernetics, 1997. Computational Cybernetics and Simulation, 1997 IEEE International Conference on, vol. 5, pp. 4104-4108, 1997.

[39] H. Ma and S. M. Shahidehpour, "Transmission-constrained unit commitment based on Benders decomposition," International Journal of Electrical Power \& Energy Systems, vol. 20, no. 4, pp. 287-294, 1998.

[40] A. H. Mantawy, et al., "A simulated annealing algorithm for unit commitment," IEEE Transactions on Power Systems, vol. 13, no. 1, pp. 197-204, 1998.

[41] A. I. Cohen, et al., "Security constrained unit commitment for open markets," in Power Industry Computer Applications, 1999, PICA'99, Proceedings of the 21st 1999 IEEE International Conference, pp. 39-44, 1999.

[42] H. Ma and S. M. Shahidehpour, "Unit commitment with transmission security and voltage constraints," IEEE transactions on power systems, vol. 14, no. 2, pp. 757-764, 1999.

[43] M. Madrigal and V. H. Quintana, "An interior-point/cutting-plane method to solve unit commitment problems," in Power Industry Computer Applications, 1999, PICA'99, Proceedings of the 21st 1999 IEEE International Conference, pp. 203-209, 1999.

[44] J. P. Painuly, "Barriers to renewable energy penetration; a framework for analysis," Renewable energy, vol. 24, no. 1, pp. 73-89, 2001.

[45] J. M. Arroyo and A. J. Conejo, "Optimal response of a thermal unit to an electricity spot market," IEEE Transactions on power systems, vol. 15, no. 3, pp. 1098-1104, 2000.

[46] M. P. Nowak and W. Römisch, "Stochastic Lagrangian relaxation applied to power scheduling in a hydro-thermal system under uncertainty," Annals of Operations Research, vol. 100, no. 1-4, pp. 251-272, 2000.

[47] S. J. Huang, "Enhancement of hydroelectric generation scheduling using ant colony system based optimization approaches," IEEE Transactions on Energy Conversion, vol. 16, no. 3, pp. 296-301, 2001.

[48] N. S. Sisworahardjo and A. A. El-Keib, "Unit commitment using the ant colony search algorithm," in Power Engineering 2002 Large Engineering Systems Conference on, LESCOPE 02, pp. 2-6, 2002.

[49] T. Nagata, et al., "A multi-agent approach to unit commitment problems," in Power Engineering Society Winter Meeting, vol. 1, pp. 64-69, 2002.

[50] T. O. Ting, et al., "Solving unit commitment problem using hybrid particle swarm optimization," Journal of heuristics, vol. 9, no. 6, pp. 507-520, 2003.

[51] G. W. Chang, et al., "A practical mixed integer linear programming based approach for unit commitment," in Power Engineering Society General Meeting, IEEE, pp. 221-225, 2004.

[52] J. Yu, et al., "Solution of the profit-based unit commitment problem by using multi-agent system," in Intelligent Control and Automation, WCICA 2004. Fifth World Congress on, vol. 6, pp. 5079-5083, 2004

[53] Y. Fu, et al., "Security-constrained unit commitment with AC constraints," IEEE transactions on power systems, vol. 20, no. 3, pp. 1538-1550, 2005.

[54] T. Li and M. Shahidehpour, "Price-based unit commitment: A case of Lagrangian relaxation versus mixed integer programming," IEEE transactions on power systems, vol. 20, no. 4, pp. 2015-2025, 2005. 
[55] J. C. Smith, et al., "Utility wind integration and operating impact state of the art," IEEE transactions on power systems, vol. 22, no. 3, pp. 900-908, 2007.

[56] E. Delarue and W. D'haeseleer, "Advanced priority listing versus mixed integer programming in solving the unit commitment problem," 2007.

[57] F. Bouffard and F. D. Galiana, "Stochastic security for operations planning with significant wind power generation," in Power and Energy Society General Meeting-Conversion and Delivery of Electrical Energy in the 21st Century, pp. 1-11, 2008.

[58] P. A. Ruiz, et al., "Applying stochastic programming to the unit commitment problem," in Probabilistic Methods Applied to Power Systems, 2008. PMAPS'08. Proceedings of the 10th International Conference on, pp. 1-6, 2008.

[59] H. Mori and K. Ohkawa, "Application of hybrid meta-heuristic method to unit commitment in power systems," in Electric Power Conference, 2008, EPEC 2008, IEEE Canada, pp. 1-5, 2008.

[60] A. Frangioni, et al., "Tighter approximated MILP formulations for unit commitment problems," IEEE Transactions on Power Systems, vol. 24, no. 1, pp. 105-113, 2009.

[61] J. Wang, et al., "Impact of wind power forecasting on unit commitment and dispatch," in Proc. 8th Int. Workshop Large-Scale Integration of Wind Power into Power Systems, pp. 1-8, 2009.

[62] J. M. Morales, et al., "Economic valuation of reserves in power systems with high penetration of wind power," IEEE Transactions on Power Systems, vol. 24, no. 2, pp. 900-910, 2009.

[63] P. A. Ruiz, et al., "Uncertainty management in the unit commitment problem," IEEE Transactions on Power Systems, vol. 24, no. 2, pp. 642-651, 2009.

[64] Antonio J., "Conejo Miguel Carrión Decision Making Under Uncertainty in Electricity Markets International Series in Operations Research \& Management Science," 2010.

[65] P. A. Ruiz, et al., "Modeling approaches for computational cost reduction in stochastic unit commitment formulations," IEEE Transactions on Power Systems, vol. 25, no. 1, pp. 588-589, 2010.

[66] S. Abedi, et al., "Risk-constrained unit commitment of power system incorporating PV and wind farms," ISRN Renewable Energy, 2011.

[67] J. Wang, et al., "Wind power forecasting uncertainty and unit commitment," Applied Energy, vol. 88, no. 11, pp. 4014-4023, 2011.

[68] J. Ostrowski, et al., "Tight mixed integer linear programming formulations for the unit commitment problem," IEEE Transactions on Power Systems, vol. 27, no. 1, pp. 39-46, 2012.

[69] Q. Wang, et al., "A chance-constrained two-stage stochastic program for unit commitment with uncertain wind power output," IEEE Transactions on Power Systems, vol. 27, no. 1, pp. 206-215, 2012.

[70] G. M. España, et al., "Tight and compact MILP formulation of start-up and shut-down ramping in unit commitment," IEEE Transactions on Power Systems, vol. 28, no. 2, pp. 1288-1296, 2013.

[71] G. M. España, et al., "Tight and compact MILP formulation for the thermal unit commitment problem," IEEE Transactions on Power Systems, vol. 28, no. 4, pp. 4897-4908, 2013.

[72] A. Viana and J. P. Pedroso, "A new MILP-based approach for unit commitment in power production planning," International Journal of Electrical Power \& Energy Systems, vol. 44, no. 1, pp. 997-1005, 2013.

[73] Q. Wang, et al., "Stochastic unit commitment with uncertain demand response," IEEE Transactions on power systems, vol. 28, no. 1, pp. 562-563, 2013.

[74] D. Sharma, et al., "Multi-agent modeling for solving profit based unit commitment problem," Applied Soft Computing, vol. 13, no. 8, pp. 3751-3761, 2013.

[75] G. M. España, et al., "An MIP formulation for joint market-clearing of energy and reserves based on ramp scheduling," IEEE Transactions on Power Systems, vol. 29, no. 1, pp. 476-488, 2014.

[76] A. S. Brouwer, et al., "Impacts of large-scale Intermittent Renewable Energy Sources on electricity systems, and how these can be modeled," Renewable and Sustainable Energy Reviews, vol. 33, pp. 443-466, 2014.

[77] H. Pandžić, et al., "Toward cost-efficient and reliable unit commitment under uncertainty," IEEE Transactions on Power Systems, vol. 31, no. 2, pp. 970-982, 2016.

[78] T. Schulze and K. McKinnon, "The value of stochastic programming in day-ahead and intra-day generation unit commitment," Energy, vol. 101, pp. 592-605, 2016.

[79] L. Yang, et al., "A novel projected two-binary-variable formulation for unit commitment in power systems," Applied Energy, vol. 187, pp. 732-745, 2017.

[80] W. Hickman, et al., "The synergistic role of renewable energy integration into the unit commitment of the energy water nexus," Renewable Energy, vol. 108, pp. 220-229, 2017.

[81] I. N. Sam'on, et al., "Ant Lion Optimizer for Solving Unit Commitment Problem in Smart Grid System," Indonesian Journal of Electrical Engineering and Computer Science, vol. 8, no. 1, 2017.

[82] S. S. Sakthi, et al., "Wind Integrated Thermal Unit Commitment Solution Using Grey Wolf Optimizer," International Journal of Electrical and Computer Engineering, vol. 7, no. 5, pp. 2309, 2017.

[83] S. H. Hosseini, et al., "A novel straightforward unit commitment method for large-scale power systems," IEEE transactions on power systems, vol. 22, no. 4, pp. 2134-2143, 2007.

[84] B. Saravanan, et al., "A solution to the unit commitment problem--a review," Frontiers in Energy, vol. 7, no. 2, pp. 223, 2013.

[85] J. Valenzuela and M. Mazumdar, "Making unit commitment decisions when electricity is traded at spot market prices," in Power Engineering Society Winter Meeting, 2001. IEEE, vol. 3, pp. 1509-1512, 2001.

[86] T. J. Larsen, et al., "Sequential timestep unit commitment," in Power Engineering Society Winter Meeting, vol. 3, pp. 1524-1529, 2001.

[87] M. Tahanan, et al., "Large-scale unit commitment under uncertainty: a literature survey," 2014. 
[88] T. Senjyu, et al., "Emerging solution of large-scale unit commitment problem by stochastic priority list," Electric Power Systems Research, vol. 76, no. 5, pp. 283-292, 2006.

[89] I. A. Farhat and M. E. El-Hawary, "Optimization methods applied for solving the short-term hydrothermal coordination problem," Electric Power Systems Research, vol. 79, no. 9, pp. 1308-1320, 2009.

[90] X. Guan, et al., "Optimization based methods for unit commitment: Lagrangian relaxation versus general mixed integer programming," in Power Engineering Society General Meeting, 2003, IEEE, vol. 2, pp. 1095-1100, 2003.

[91] P. A. Ruiz, et al., "Applying stochastic programming to the unit commitment problem," in Probabilistic Methods Applied to Power Systems, 2008. PMAPS'08. Proceedings of the 10th International Conference on, pp. 1-6, 2008.

[92] T. Sawa, et al., "Security constrained integrated unit commitment using quadratic programming," in Power Tech, 2007 IEEE Lausanne, pp. 1858-1863, 2007.

[93] B. F. Hobbs, et al., "The next generation of electric power unit commitment models," Springer Science \& Business Media, vol. 36, 2006.

[94] C. L. Chen and S. C. Wang, "Branch-and-bound scheduling for thermal generating units," IEEE transactions on energy conversion, vol. 8, no. 2, pp. 184-189, 1993.

[95] J. P. D. S. Catalão, et al., "Mixed-integer nonlinear approach for the optimal scheduling of a head-dependent hydro chain," Electric Power Systems Research, vol. 80, no. 8, pp. 935-942, 2010.

[96] N. M. Shadaksharappa, "Optimum generation scheduling for thermal power plants using artificial neural network," International Journal of Electrical and Computer Engineering, vol. 1, no. 2, pp. 134, 2011.

[97] G. Dudek, "Adaptive simulated annealing schedule to the unit commitment problem," Electric Power Systems Research, vol. 80, no. 4, pp. 465-472, 2010.

[98] A. H. Mantawy, et al., "Integrating genetic algorithms, tabu search, and simulated annealing for the unit commitment problem," IEEE Transactions on Power systems, vol. 14, no. 3, pp. 829-836, 1999.

[99] C. A. Rajan, "An evolutionary programming based tabu search method for unit commitment problem with coolingbanking constraints, ” in Power India Conference, 2006 IEEE, pp. 8, 2006.

[100] H. Mori and T. Usami, "Unit commitment using tabu search with restricted neighborhood," in Intelligent Systems Applications to Power Systems, 1996. Proceedings, ISAP'96, International Conference on, pp. 422-427, 1996.

[101] V. Selvi and D. R. Umarani, "Comparative analysis of ant colony and particle swarm optimization techniques," International Journal of Computer Applications, vol. 5, no. 4, 2010.

[102] M. Clerc and J. Kennedy, "The particle swarm-explosion, stability, and convergence in a multidimensional complex space," IEEE transactions on Evolutionary Computation, vol. 6, no. 1, pp. 58-73, 2002.

[103] O. Abedinia, et al., "Multi-objective environmental/economic dispatch using firefly technique," in Environment and Electrical Engineering (EEEIC), 2012 11th International Conference on, pp. 461-466, 2012.

[104] S. Saneifard, et al., "A fuzzy logic approach to unit commitment," IEEE Transactions on Power Systems, vol. 12, no. 2, pp. 988-995, 1997.

[105] S. H. Li, et al., "Promoting the application of expert systems in short-term unit commitment," IEEE Transactions on Power Systems, vol. 8, no. 1, pp. 286-292, 1993.

[106] W. Chang and X. Luo, "A solution to the unit commitment using hybrid genetic algorithm," in TENCON 20082008 IEEE Region 10 Conference, pp. 1-6, 2008. 